\title{
A RELAÇÃO DOS ALUNOS DO CURSO DE PEDAGOGIA COM O CONHECIMENTO MATEMÁTICO E SEU ENSINO: UM ESTUDO LONGITUDINAL
}

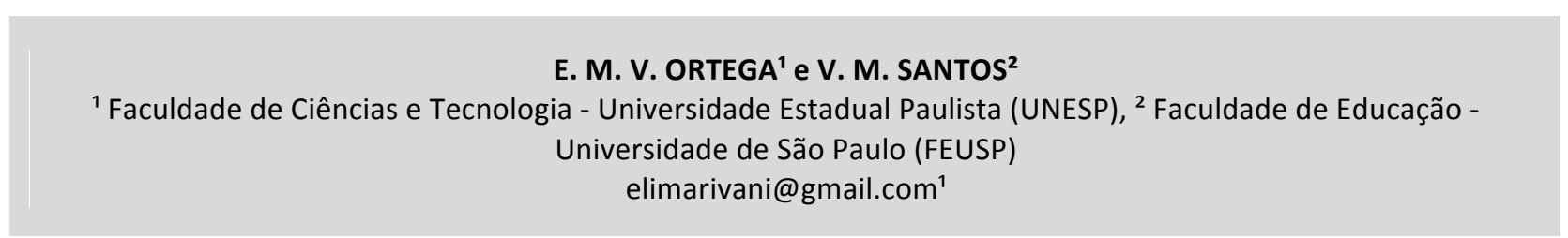

Submetido 03/03/2017 - Aceito 20/02/2018

DOI: $10.15628 /$ holos.2018.5724

\section{RESUMO}

O presente estudo está inserido no campo da Educação Matemática e de forma mais direta relaciona-se à formação dos professores que ensinam Matemática nos anos iniciais do Ensino Fundamental. Trata-se de levantamento descritivo-analítico, no contexto de uma abordagem qualitativa por meio de estudo longitudinal. O estudo foi realizado com estudantes do curso de Pedagogia que ingressaram no curso em 2007 e o concluíram no ano de 2010. Apresentamos resultados sobre a relação dos alunos com o conhecimento matemático e seu ensino durante o período de formação inicial. A partir de textos produzidos pelos sujeitos da pesquisa ao final de cada ano do curso de Pedagogia (2007, 2008, 2009 e 2010), visualizamos alterações em relação ao conhecimento matemático e seu ensino. Tais alterações indicam que eles terminam o curso mais próximos do conhecimento matemático, afirmam a necessidade de constante estudo sobre essa área e há rupturas de crenças como aquelas relacionadas à matemática ser inacessível. Também percebemos preocupação dos sujeitos com a relação professor-aluno no processo de ensino e aprendizagem da Matemática bem como com a utilização de atividades diversificadas, brincadeiras, jogos, necessidade de explicar os conceitos de diferentes formas, utilização de diferentes materiais didáticos, necessidade de mostrar aplicações dos conceitos matemáticos.

PALAVRAS-CHAVE: Conhecimento matemático, Ensino de Matemática, Pedagogia, Estudo Longitudinal.

\section{THE RELATION OF THE STUDENTS OF PEDAGOGY'S COURSE WITH THE MATHEMATICAL KNOWLEDGE AND ITS TEACHING: A LONGITUDINAL STUDY}

\begin{abstract}
This essay is included in the field of Mathematic Education and of more direct way is related to formation of the teachers that teach Mathematic in the initial years of the Elementary Level. It is about analytical-descriptive lifting by longitudinal study, in the context of a qualitative approach. The study was done with students of the course of Pedagogy that began it at 2007 and the concluded at 2010. We present results about the relation of the students with the mathematical knowledge and its teaching during the period of initial formation. From texts produced by subjects of the research at the end of each year of the course of Pedagogy (2007, 2008, 2009 e 2010), we
\end{abstract}

visualized changes in relation to mathematical knowledge and its teaching. These changes indicate that they finish the course closer of the mathematical knowledge, highlight the necessity of constant study about this field and there are ruptures of beliefs like those related to mathematics being inaccessible. We also realized worry of the subjects with the relation between teacher and students in the process of teaching and learning as well with the use of diversified activities, jokes, games, necessity of explaining the concepts in different ways, use of different didactic material, necessity of showing a importance of apply the mathematics concepts.

KEYWORDS: Mathematical knowledge, Teaching of Mathematic, Pedagogy, Longitudinal Study. 


\section{INTRODUÇÃO}

A preocupação com a formação matemática dos futuros professores dos anos iniciais está presente nos resultados das pesquisas em Educação Matemática tanto no Brasil como em outros países.

Para Stephens (2003), é fundamental que os futuros professores da escola primária tenham forte compreensão da matemática a ser ensinada e também dos procedimentos a serem utilizados e que na maioria dos países os programas de formação não tem conseguido contemplar tais questões.

Cooney \& Wiegel (2003) consideram que a preparação matemática dos professores para os anos iniciais utilizada em vários países têm características diferentes, mas que apontam para algo em comum- professores da escola elementar, ao participarem de testes, mesmo quando acertam determinadas questões matemáticas, em geral demonstram que não conseguem elaborar explicações consistentes ou relações entre diferentes tópicos. Esses autores defendem que a formação desses professores deveria incluir a experimentação da matemática como um assunto pluralista, reflexão sobre a matemática a ser ensinada na escola e vivência dessa disciplina como processo.

Consideramos que os conhecimentos de conteúdo matemático a serem ensinados nos anos iniciais devem ser estudados pelos futuros professores de forma relacionada ao conhecimento pedagógico desses conteúdos. Ainda, cumpre salientar que não basta estudar os conceitos específicos e procedimentos metodológicos que envolvem os diferentes campos da Matemática que serão ensinados nos anos iniciais. É preciso considerar diferentes questões que envolvem o processo de acesso ao conhecimento matemático. Trata-se, portanto, de se dar atenção a reflexões que podem ser feitas sobre a natureza do conhecimento matemático. Parte das dificuldades de professores e alunos em relação à aprendizagem da matemática ensinada na escola está relacionada à forma como esse conhecimento tem sido compreendido e difundido ao longo de sua produção.

Reformas curriculares ocorridas no Brasil nos últimos anos sugerem práticas que em teoria deveriam produzir resultados satisfatórios em relação ao acesso ao conhecimento matemático, mesmo considerando as limitações que em geral envolvem o processo de implementação de tais reformas. Entretanto, o que se constata em diferentes pesquisas do campo da Educação Matemática é que ainda persistem práticas baseadas na memorização de conteúdos e compreensão superficial dos conceitos dos diferentes campos da Matemática. Entendemos que parte dessa situação está relacionada à ausência de reflexão sobre a natureza do conhecimento matemático. Um indivíduo que considera a matemática como um conjunto de algoritmos e definições prontas a serem memorizadas e praticadas por meio da resolução de exercícios e problemas, pode não perceber a importância do processo de construção e reflexão que envolve esse conhecimento.

De acordo com Santos (2008, p. 2.), diferentes orientações têm acompanhado o ensino de matemática nas escolas, vindas dos matemáticos, educadores e sociedade. Tais orientações têm 
sido baseadas em algoritmos, descobertas matemáticas, diferentes procedimentos de ensino, recursos didáticos. Entretanto, mesmo com tal diversidade, a Matemática "segue inacessível a grande parte dos alunos". Tal fato tem impacto na formação dos professores dos anos iniciais, já que de acordo com Tardif (2010), os anos vividos como alunos são parte da formação desses professores.

O fato de durante muito tempo a Matemática ter sido considerada como um conjunto de conhecimentos formado por verdades inquestionáveis, precisas, contribuiu para afastar muitos indivíduos de tal conhecimento. Essa visão do conhecimento matemático dificulta o acesso ao saber matemático na medida em que muitos indivíduos consideram necessário possuir habilidades especiais para a aprendizagem de tal conhecimento.

Ernest (2004), ao investigar atitudes e crenças de professores sobre a matemática, revela que as experiências escolares confirmam a imagem absolutista da matemática, ou seja, a de uma área de conhecimento repleta de verdades inquestionáveis e não sujeita a erros. $\mathrm{O}$ autor defende posições falibilistas, que tecem severas críticas ao absolutismo. Tais posições defendem que a matemática é corrigível, falível, aberta à revisão e um produto de mudança social. Ainda, discordam que as verdades matemáticas são absolutas, pois as provas dedutivas de um teorema ou proposição matemática partem de suposições iniciais, as quais nem sempre são verdades absolutas. Os falibilistas compreendem que a matemática está envolvida na história e prática humana e dessa forma está sujeita a erros.

As experiências vivenciadas na Educação Básica com a Matemática terão desdobramentos na atividade docente e não apenas as disciplinas cursadas no curso de formação inicial. Daí a importância que, durante esta formação, os futuros professores possam desenvolver uma base conceitual relativa a diferentes conteúdos matemáticos, fundamentos metodológicos e recursos didáticos abordados na educação básica e, associado a isso, possam refletir sobre a natureza da Matemática, valorizando a riqueza dos processos de construção, o caráter falível e sujeito a erros.

Consideramos que estas questões devem fazer parte do processo de formação inicial dos professores de matemática dos anos iniciais. Concordamos com Azcárate (1999), que defende a importância dos saberes docentes irem além dos conteúdos disciplinares dos cursos de formação o que significa, no caso da matemática, que sejam contemplados também a sua natureza, a sua origem e próprio processo de produção histórica das ideias matemáticas. Os professores em formação precisam compreender a natureza do conhecimento matemático, para que tenham condições de compreender o sentido dos diferentes conceitos que irão ensinar a seus alunos bem como os diferentes contextos nos quais tais conceitos adquirem significados.

A partir do contexto enunciado, desenvolvemos o presente trabalho. Investigamos sujeitos que iniciaram o curso de Pedagogia no ano de 2007 em uma Universidade Pública do Estado de São Paulo e o concluíram no ano de 2010. Em todo esse período acompanhamos um grupo de alunos do curso de Pedagogia por meio de entrevistas semiestruturadas e produção de textos ao final de cada ano cursado. Neste estudo longitudinal focalizamos a relação dos alunos do curso de Pedagogia com o conhecimento matemático e seu ensino no decorrer do curso tomando como material de análise os textos produzidos nos quatro anos de formação. 


\section{O CONHECIMENTO MATEMÁTICO NA FORMAÇÃO DOS PROFESSORES DOS ANOS INICIAIS DO ENSINO FUNDAMENTAL}

Na primeira escola normal brasileira instalada em 1835, na Província do Rio de Janeiro, observamos que o objetivo em relação ao ensino da Matemática se resumia a transmitir alguns conteúdos. O foco principal era dado aos cálculos numéricos. De acordo com Curi (2005), a partir do século $X X$, é que começam a surgir nos programas das escolas primárias, conteúdos que iam além da Aritmética, como Geometria, por exemplo, e preocupações de caráter metodológico. Tal fato se dá em razão da influência dos estudos da Pedagogia e Psicologia.

A partir da LDBEN 5692/71, os cursos em nível médio de habilitação para o magistério continham na área de Ciências, disciplina voltada para a Didática da Matemática, mas sem trabalho sistemático com todos os conteúdos a serem ensinados nos anos iniciais. A partir dos anos 80, com o início do Projeto do Centro Específico de Formação e Aperfeiçoamento do Magistério (CEFAM) em vários estados do Brasil, e especificamente no Estado de São Paulo, em 1988, surge a disciplina Conteúdos e Metodologia das Ciências e da Matemática. (Curi, 2005)

Apesar dos avanços obtidos sob a estrutura do CEFAM, segundo Nacarato, Mengali e Passos (2009, p17), na maioria das vezes, a disciplina específica voltada para a Matemática era trabalhada por pedagogos sem formação específica na área, o que acarretava "uma formação com muitas lacunas conceituais nessa área do conhecimento". Para essas autoras, nesse período, os cursos de Pedagogia, diferente do CEFAM, nem chegavam a ter disciplina específica voltada para a Matemática. A disciplina Metodologia do Ensino de 10 Grau tinha que dar conta de todas as áreas e era ministrada por pedagogo, que na maioria das vezes enfatizava aspectos gerais de metodologias de ensino.

Para Curi (2005), nos anos 80, as reformulações dos cursos de Pedagogia não alteraram a situação da Matemática na formação inicial dos professores polivalentes. As pesquisas em Educação nesse período, no que diz respeito à formação de professores, estavam mais voltadas para as metodologias de ensino e não chegavam a ter como foco os objetos de ensino das diferentes áreas, incluindo o conhecimento matemático. Dessa forma, a Matemática seguia praticamente ausente da formação inicial dos professores polivalentes.

Apenas a partir da Lei 9.394/96, temos de forma explícita nas Diretrizes Curriculares Nacionais para a Formação de Professores de 2002, a preocupação com os objetos de ensino. De acordo com tais diretrizes, a formação dos docentes deve contemplar competências relacionadas ao domínio dos conteúdos, aos seus significados em diferentes contextos e à sua articulação interdisciplinar.

A partir de 2006, também as Diretrizes Curriculares Nacionais para o Curso de Pedagogia, em seu artigo 5으, item VI afirmam que o egresso do curso de Pedagogia deverá estar capacitado a "ensinar Língua Portuguesa, Matemática, Ciências, História, Geografia, Artes, Educação Física, de forma interdisciplinar e adequada às diferentes fases do desenvolvimento humano." (Diário Oficial da União, 2006, p. 11). 
Apesar do avanço em relação à valorização dos objetos de ensino das diferentes áreas, de modo geral, a carga horária dedicada à formação matemática nos cursos de Pedagogia tem sido insuficiente.

Curi (2005), ao analisar grades curriculares dos cursos de Pedagogia e do Curso Normal Superior, mais precisamente, grades que foram reformuladas a partir de 2000, antes da publicação das novas diretrizes, constatou a presença, na maioria das grades (66\%), de uma disciplina denominada Metodologia de Ensino de Matemática e em 25\%, a disciplina Conteúdos e Metodologia de Ensino de Matemática. De acordo com a autora, as ementas dos cursos são muito diferentes entre si mesmo quando apresentam o mesmo nome para as disciplinas e a maioria delas revela uma tendência voltada para aspectos metodológicos.

A partir das Diretrizes Curriculares Nacionais para o Curso de Pedagogia de 2006, tais cursos precisaram se adaptar no sentido de abordar de forma mais explícita metodologias de ensino envolvendo os objetos de ensino das diferentes áreas a serem ensinadas nos anos iniciais do Ensino Fundamental. Entretanto, tais diretrizes apresentam inúmeras funções para os Pedagogos, que geram dúvidas se os cursos têm conseguido dar conta de todas elas e preparar o professor para o ensino de Geografia, História, Ciências, Artes, Língua Portuguesa, Educação Física e Matemática.

Quanto aos cursos de graduação em Pedagogia, somente em 2006, depois de muitos debates, o Conselho Nacional de Educação aprovou a Resolução n. 1, de 15/05/2006, com as Diretrizes Curriculares Nacionais para esses cursos, propondo-os como licenciatura e atribuindo a estes a formação de professores para a educação infantil e anos iniciais do ensino fundamental, bem como para o ensino médio na modalidade Normal, onde fosse necessário e onde esses cursos existissem, e para a educação de jovens e adultos, além da formação de gestores. Essa licenciatura passa a ter amplas atribuições, embora tenha como eixo a formação de docentes para os anos iniciais da escolarização. (Gatti, 2010, p. 1357)

De acordo com Gatti (2010, p. 1368.), estudos de Gatti \& Nunes (2008), a partir da análise de 71 cursos de Pedagogia do Brasil, revelam que:

O grupo “Didáticas Específicas, Metodologias e Práticas de Ensino" (o "como" ensinar) representa $20,7 \%$ do conjunto, e apenas $7,5 \%$ das disciplinas são destinadas aos conteúdos a serem ensinados nas séries iniciais do ensino fundamental, ou seja, ao "o que" ensinar. Esse dado torna evidente como os conteúdos específicos das disciplinas a serem ministradas em sala de aula não são objeto dos cursos de formação inicial do professor.

De acordo com tais estudos são poucas as instituições que tratam dos conceitos específicos a serem ensinados nos anos iniciais durante a formação inicial e quando o fazem é de forma panorâmica e sem o aprofundamento adequado. 


\section{METODOLOGIA}

A pesquisa completa relacionada a este artigo foi desenvolvida como tese de doutorado cujo objetivo geral era investigar qual a contribuição do curso de Pedagogia no processo de constituição dos saberes de um grupo de alunos deste curso em relação à natureza do conhecimento matemático (o que é a Matemática e para que ela serve), e seu ensino (quais são as hipóteses sobre o ensino da Matemática que esses professores em formação possuem). Tal pesquisa se caracteriza como um levantamento descritivo-analítico e comparativo, no contexto de uma abordagem qualitativa. Trata-se de um estudo longitudinal, realizado durante quatro anos, de 2007 a 2010.

Inicialmente, aplicamos a todos os ingressantes do curso de Pedagogia um questionário indagando sobre dados pessoais e profissionais, interesse em participar da pesquisa, e sobre a relação que tinham com a Matemática. Selecionamos nove sujeitos a partir dos seguintes critérios: concordância em participar do estudo durante os quatro anos; experiência como professor; nenhuma experiência como professor; relação com a Matemática (péssima, regular, boa e ótima).

A partir da definição dos sujeitos, elaboramos um roteiro de entrevista semiestruturada que foi aplicada nos meses de novembro e dezembro de 2007. Tais entrevistas foram gravadas, transcritas manualmente e a seguir digitalizadas. A partir das primeiras análises, os roteiros para os anos de 2008, 2009 e 2010 sofreram pequenas modificações sempre respeitando a estrutura inicial para facilitar e dar maior coerência à análise dos dados obtidos.

A escolha da entrevista semiestruturada permitiu uma maior flexibilidade e possibilitou as adequações necessárias nos roteiros ao longo do estudo. Segundo Lüdke \& André (1986, p. 34.), “a grande vantagem da entrevista sobre outras técnicas é que ela permite a captação imediata e corrente da informação desejada, praticamente com qualquer tipo de informante e sobre os mais variados tópicos".

De acordo com Hitchcock \& Hughes (1995), a entrevista semiestruturada permite aos pesquisadores na área de educação, um conhecimento mais profundo do que está sendo investigado, já que possibilita ao entrevistador fazer intervenções no sentido de expandir as repostas dos sujeitos entrevistados. Outras vantagens estão relacionadas ao contato próximo na coleta de dados, o que pode auxiliar na análise das informações.

Organizamos a entrevista em quatro partes. A primeira, fundamental para um estudo longitudinal, solicitava informações gerais como endereço, telefone e e-mail, para facilitar a localização dos sujeitos ao longo do período de desenvolvimento da pesquisa. A segunda parte eram questões sobre a atuação profissional dos sujeitos: se os sujeitos trabalhavam, qual o tipo de trabalho; se participavam de atividades acadêmicas na universidade, em quais projetos estavam envolvidos. A terceira parte continha questões relacionadas à natureza do conhecimento matemático e seu ensino e envolvia questões sobre as razões que justificam a presença do ensino da Matemática no currículo dos anos iniciais do Ensino Fundamental, quais eram os conteúdos que os sujeitos se lembravam de ter estudado durante sua formação na Educação Básica, e solicitava a descrição das suas experiências como alunos em relação à aprendizagem da Matemática, à visão que eles tinham dos professores de Matemática que tiveram em toda a 
trajetória escolar e à maneira como eles se relacionavam com a ideia de serem professores de Matemática nos anos iniciais. Na quarta parte da entrevista, os sujeitos, através da produção de um texto, descreveram a forma como os conhecimentos aprendidos em cada ano do curso de Pedagogia influenciaram os saberes/significados que eles possuíam sobre a Matemática e seu ensino.

Neste artigo apresentamos os resultados da quarta parte, mais explicitamente, relacionados aos textos produzidos nos quatro anos do estudo longitudinal. Para Poli (2007), os estudos longitudinais são pouco utilizados no Brasil, em geral, devido ao tempo que exigem para a sua consecução. Nem sempre é possível financiamentos de longo prazo e o tempo destinado a pesquisas de mestrado e doutorado são insuficientes para estudos longitudinais. Em sua tese de doutorado Poli (2007) realizou estudo longitudinal, tomando como referência um projeto de avaliação desenvolvido numa parceria entre a Universidade de Exeter, na Inglaterra e a Universidade Estadual de Londrina-Paraná, no Brasil. Tal estudo consistiu no monitoramento de alunos que participaram de uma avaliação internacional desde a 7ạ série do Ensino Fundamental ${ }^{1}$ até a 1a série do Ensino Médio. Estes alunos eram submetidos a testes de Matemática e em cada ano os resultados eram comparados, utilizando-se ferramentas estatísticas.

Bonamino \& Oliveira (2013, p. 40) afirmam que os estudos longitudinais permitem "analisar o quanto as práticas escolares contribuem para o aprendizado dos alunos durante o ano em que eles frequentam uma escola".

Os estudos longitudinais em Educação têm sido mais comuns nos últimos anos, mas voltados para a área de avaliação, com objetivos de testar alunos mais de uma vez, no que diz respeito a domínio de conteúdos específicos de diferentes áreas do conhecimento. Neste trabalho, o estudo longitudinal tem como foco a compreensão dos saberes sobre o conhecimento matemático e seu ensino durante o processo de toda a formação inicial no curso de Pedagogia.

\section{RESULTADOS E DISCUSSÕES}

\subsection{Perfil dos sujeitos}

Inicialmente apresentamos o perfil dos sujeitos participantes do estudo longitudinal. 0 quadro a seguir descreve a sua idade, a relação com a Matemática quando ingressaram no curso de Pedagogia, a sua atuação profissional e a razão da escolha pelo curso.

${ }^{1}$ Atual oitavo ano do Ensino Fundamental 


\begin{tabular}{|c|c|c|c|c|c|}
\hline Sujeitos & Idade & Sexo & $\begin{array}{l}\text { Relação com a } \\
\text { Matemática }\end{array}$ & $\begin{array}{c}\text { Atuação } \\
\text { Profissional } 2007\end{array}$ & $\begin{array}{c}\text { Porque escolheram o Curso de } \\
\text { Pedagogia }\end{array}$ \\
\hline S1 & 19 & $\mathrm{~F}$ & Boa. & Não trabalha. & $\begin{array}{l}\text { Desejo de fazer Terapia } \\
\text { Ocupacional. } \\
\text { Objetivo de fazer mestrado. } \\
\text { Não pensa em exercer a } \\
\text { docência nos anos iniciais. }\end{array}$ \\
\hline S2 & 18 & $\mathrm{~F}$ & Regular. & Não trabalha. & $\begin{array}{l}\text { Era sua terceira opção. } \\
\text { Pensa em exercer a docência } \\
\text { nos anos iniciais. }\end{array}$ \\
\hline S3 & 18 & $\mathrm{~F}$ & Ruim. & Babá. & $\begin{array}{l}\text { Queria Geografia. } \\
\text { Não pensa em exercer a } \\
\text { docência nos anos iniciais. }\end{array}$ \\
\hline S4 & 37 & $\mathrm{~F}$ & Péssima. & Escriturária Escolar. & $\begin{array}{l}\text { Queria Geografia. } \\
\text { Gosta de crianças. }\end{array}$ \\
\hline S5 & 18 & $\mathrm{~F}$ & Regular. & $\begin{array}{lr}\text { Auxiliar } & \text { de Ensino } \\
\text { na } & \text { Educação } \\
\text { Infantil. } & \\
\end{array}$ & Gosta de crianças. \\
\hline S6 & 23 & $\mathrm{M}$ & Ótima. & $\begin{array}{l}\text { Professor das séries } \\
\text { iniciais e professor } \\
\text { de Geografia no } \\
\text { Ensino Médio. }\end{array}$ & $\begin{array}{l}\text { Interesse pelas questões } \\
\text { educacionais. } \\
\text { Deseja assumir a coordenação } \\
\text { pedagógica, direção ou } \\
\text { supervisão. }\end{array}$ \\
\hline S7 & 19 & $\mathrm{~F}$ & Regular. & $\begin{array}{l}\text { Auxiliar de Ensino } \\
\text { nas séries iniciais. }\end{array}$ & $\begin{array}{l}\text { Sempre quis exercer a } \\
\text { docência nos anos iniciais. }\end{array}$ \\
\hline S8 & 27 & $M$ & Ótima. & $\begin{array}{l}\text { Professor de Língua } \\
\text { Portuguesa no } \\
\text { Ensino Médio. }\end{array}$ & Interesse pela Educação. \\
\hline S9 & 27 & $\mathrm{~F}$ & Boa. & $\begin{array}{l}\text { Professora de } \\
\text { Filosofia no Ensino } \\
\text { Médio. }\end{array}$ & $\begin{array}{l}\text { Deseja fazer o mestrado e } \\
\text { exercer funções relacionadas à } \\
\text { supervisão ou direção. }\end{array}$ \\
\hline
\end{tabular}

Quadro 1: Perfil dos sujeitos entrevistados no ano de $2007-1^{\circ}$ ano do curso de pedagogia

Como consta no Quadro 1, os sujeitos envolvidos na pesquisa são em sua maioria jovens do sexo feminino. Dos nove sujeitos, apenas dois são do sexo masculino. Aproximadamente metade dos sujeitos apresentava idade entre 18 e 19 anos quando ingressaram no curso no ano de 2007. Tais sujeitos vieram diretamente para o curso de Pedagogia após concluírem o Ensino Médio. Três sujeitos apresentavam entre 23 e 27 anos e já exerciam a profissão de professor (Geografia, Língua Portuguesa e Filosofia). Um dos sujeitos, com mais de 30 anos, ingressou no curso após vários anos da conclusão do Ensino Médio.

Dentre os sujeitos que não pensavam o curso de Pedagogia como primeira opção, alguns afirmavam não ter interesse em exercer a docência nos anos iniciais e viam o curso de Pedagogia como uma forma de fazer mestrado ou pelo fato de gostarem de crianças.

Outra situação que aparece na pesquisa é que os sujeitos que já cursaram uma determinada graduação (S6, S8 e S9), procuraram o curso interessados no mestrado ou em assumir cargos de gestão, como coordenação pedagógica, direção e supervisão. 
No que diz respeito à relação com a Matemática, alguns sujeitos afirmam ter procurado o curso de Pedagogia utilizando como um critério importante a expectativa de que não teriam contato com a área de Matemática.

\title{
4.2. Pedagogos em formação e relações com o conhecimento matemático e seu ensino
}

Em relação ao texto que solicitamos aos alunos sobre os conhecimentos aprendidos no curso, avaliando se o que aprenderam influenciou na maneira como viam a Matemática e seu ensino, obtivemos 8 textos em cada ano (um dos sujeitos trancou o curso e não participou do estudo) num total de 32 textos ao final da pesquisa.

No ano de 2007 os sujeitos não consideraram que as disciplinas do primeiro ano ajudaram de forma específica a alterar suas visões sobre a Matemática e seu ensino, mas identificaram algumas disciplinas que contribuíram para ampliar a visão sobre questões amplas da Educação. Apareceu nas falas dos sujeitos a disciplina Psicologia da Educação, quando essa disciplina tratou das fases de aprendizagem. Fizeram menção às disciplinas que constituem fundamentos como Filosofia, História e Sociologia da Educação no sentido de auxiliar na construção de uma visão ampla e crítica da Educação como um todo e apontaram que isso seria importante também para a compreensão da Matemática.

\begin{abstract}
Neste primeiro ano de Pedagogia eu conheci um pouco da história da educação, como surgiu, alguns de seus métodos, conheci também a história da sociedade, da filosofia e a psicologia infantil que aborda o processo do crescimento das pessoas. Analisando o que eu aprendi até agora com a maneira que eu vejo a Matemática, não mudou muita coisa, e algum método referente a matemática eu acredito que a didática deve ser mais trabalhada, pois a grande maioria dos professores de matemática não são bons para passar o que sabe.(S1, 2007.). (Ortega, 2011, p.98.)
\end{abstract}

Em 2008, os sujeitos descrevem de maneira mais acentuada, as contribuições de disciplinas do segundo ano como Didática, Educação de Jovens e Adultos e Metodologia do Ensino de Artes. Referiram-se a essas disciplinas como aquelas mais voltadas para a formação do professor e que, por isso, auxiliariam no caso da Matemática. Há uma preocupação desde o ano de 2007 com as formas de ensinar dos professores de Matemática em razão dos tipos de experiência que vivenciaram como alunos na Educação Básica.

Até agora pude perceber que a Matemática está bem presente na vida das crianças, até mesmo da educação infantil com as quais trabalhei este ano, minha relação com esta matéria não foi boa enquanto aluna do ensino fundamental e médio, mas acredito que hoje já seria mais fácil ensinar as crianças os conteúdos matemáticos por conta da matéria de didática que apresenta várias maneiras de ensinar, como planejar uma aula, embora não me considere ainda apta para tal tarefa. (S2, 2008.). (Ortega, 2011, p. 99.)

No ano de 2009 foram citadas contribuições das disciplinas Metodologia e Prática de Ensino em Educação Infantil de 0 a 3 anos, Conteúdos, Metodologia e Prática de Ensino de Ciências e Conteúdos, Metodologia e Prática de Ensino de Geografia. 
Apesar de ainda não ter visto a disciplina sobre metodologia e conteúdos de matemática, pode-se dizer que para lecionar qualquer disciplina é necessário o conhecimento dela, se apropriar de alguns conceitos mínimos. É importante também que haja planejamento, estratégias e objetivos bem definidos para que aconteça o ensino /aprendizagem. Pensar em conteúdos que sejam interdisciplinares ajuda muito no entendimento do estudante e o professor das séries iniciais por ser o único responsável pela transmissão desses conteúdos, tem maior possibilidade de relacioná-los. (S9, 2009.). (Ortega, 2011, p.100.)

Percebemos nos textos produzidos, principalmente em 2009, uma maior segurança em relação ao ensino nos anos iniciais. Algumas características começam a predominar nas falas dos sujeitos: considerar o desenvolvimento cognitivo dos alunos; a importância de levar em conta as diferenças existentes entre os alunos de uma sala; a importância de partir daquilo que a criança já entende; a importância em manter um clima de respeito, atenção, paciência com as crianças; a importância de se planejar bem uma aula, de utilizar atividades lúdicas para envolver as crianças no sentido de manter o interesse pelo assunto a ser estudado.

Sim, os conteúdos aprendidos durante estes três anos da Faculdade me fizeram enxergar a Matemática de forma diferente, principalmente no ano passado quando na aula de artes, vi muitas coisas relacionadas à Matemática que dá pra trabalhar com as crianças, e também alguns conteúdos que também foram vistos nas matérias de Ciências, Geografia, neste ano e no projeto de Educação Ambiental, no qual trabalhei ao longo deste ano. Este contexto todo me fez ver a matemática de uma melhor forma, que talvez não seja um bicho de sete cabeças, como pensava antes. (S3, 2009.) (Ortega, 2011, p. 100.)

Nos três primeiros anos, os sujeitos, apesar de se sentirem mais à vontade para exercer a docência nos anos iniciais, reconhecem que é fundamental se ter uma disciplina específica para tratar da Matemática e alguns tinham receio de que esta disciplina, apenas prevista para ser cursada no quarto ano, poderia não dar conta de tantas dificuldades e medos ainda existentes.

No último ano da realização do estudo longitudinal, 2010, os sujeitos falam da contribuição da disciplina Conteúdos, Metodologia e Prática de Ensino de Matemática.

Hoje em dia eu me vejo menos preconceituosa em relação à Matemática, mas assim, eu me dou bem com a Matemática inicial que eu vou ter que ensinar, mas uma matemática que exige um pensamento muito abstrato assim eu não tenho uma relação boa, mas assim eu procuro não passar para as crianças aquele medo da Matemática, ela é uma disciplina importante como as outras são, e tem essa coisa formada que ela é mais importante e mais difícil, pra mim foi, mas hoje em dia eu me vejo mais tranquila com relação à Matemática. (S5, 2010.) (Ortega, 2011, p.103.)

O sujeito que em 2007 afirmava ter uma péssima relação com a Matemática, apesar de afirmar que aprendeu a gostar mais da Matemática, ainda mantém uma relação de cautela. Considera que se for dar aulas terá que se dedicar com afinco para aprender os conceitos a serem ensinados. 
Durante todo o curso de Pedagogia, os conhecimentos diversos não interferiram na forma ou maneira de como vejo a Matemática. Hoje, final do curso de Pedagogia, com a ajuda da professora que ministrou as aulas de matemática, aprendi a gostar mais da Matemática, pelo menos de primeira a quarta série do Ensino Fundamental. (S4, 2010.). (Ortega, 2011, p.103.)

S8 fala da contribuição de metodologia da matemática principalmente em relação à necessidade de superação da abordagem mecânica dos conteúdos, a matemática enquanto construção humana, a maneira como podem ser mostradas as aplicações dos conteúdos, formas alternativas de ensinar as operações e geometria.

Eu pude ver alguns aspectos da matemática que eram desconhecidos pra mim, principalmente os aspectos de você fazer algumas operações de maneiras alternativas porque meu aprendizado na escola sempre foi aquele aprendizado mecânico, que você aprendia as operações somente de uma maneira e então você praticamente não raciocinava a respeito da conta que você fazia [...] aprendi a enxergar com outros olhares né, ter uma visão muito mais ampla, a enxergar o número, o significado de cada posição do algarismo, ter a noção de que existem outros sistemas de numeração, que a numeração não é algo que foi dado por alguma instituição divina, que a matemática foi criada por pessoas imperfeitas, seres humanos, o homem. (S8, 2010.) (Ortega, 2011, p. 104.)

Percebemos que de modo geral os sujeitos demonstram alterações em relação à aproximação do conhecimento matemático. Cabe refletirmos se essas alterações serão suficientes para que estes sujeitos consigam trabalhar melhor com os conceitos matemáticos.

A disciplina de Conteúdos, Metodologia e Prática de Ensino de Matemática do curso na visão dos alunos investigados, apresenta características de articulação teoria e prática e é desenvolvida de forma a alterar a impressão que eles tinham sobre o nível de dificuldade e preconceitos sobre a Matemática. Ainda assim, não consegue garantir uma aproximação completa em relação aos conceitos matemáticos. Ao que parece, as mudanças precisam de um tempo maior para se consolidar e acontecem de forma diferente em cada indivíduo, já que as experiências vivenciadas pelos sujeitos enquanto alunos não se apagam num curto espaço de tempo. Daí a importância que todas as disciplinas do curso de Pedagogia estejam articuladas e voltadas para o perfil que se deseja formar.

Essas análises foram possíveis porque a partir das informações descritas nos textos, elaboramos um quadro síntese com as ideias que apareceram em cada ano, por sujeito. Assim, pudemos comparar as alterações de cada sujeito em suas descrições em cada ano. $O$ quadro completo pode ser consultado em Ortega (2011). Escolhemos para o presente artigo apresentar as principais ideias de 4 sujeitos do quadro organizado, que entendemos ser representativa do grupo investigado. Um sujeito que apresentava uma relação boa com a Matemática (RB), uma regular (RR), uma ruim (RRU) e uma péssima (RP), no início do estudo em 2007. 


\begin{tabular}{|c|c|c|c|c|}
\hline & Textos 2007 & Textos 2008 & Textos 2009 & Textos 2010 \\
\hline S1 & $\begin{array}{l}\text { - Estudo dos } \\
\text { fundamentos da } \\
\text { Educação. } \\
\text { - Não descreve } \\
\text { possíveis } \\
\text { interferências na } \\
\text { forma de ver o } \\
\text { conhecimento } \\
\text { matemático e seu } \\
\text { ensino. }\end{array}$ & $\begin{array}{l}\text { - Disciplinas mais } \\
\text { voltadas para a formação } \\
\text { dos } \\
\text { (Didática, } \quad \text { professores } \\
\text { Metodologia e Prática de } \\
\text { ensino de Artes foram } \\
\text { citadas). } \\
\text { - Os conhecimentos } \\
\text { aprendidos provocaram } \\
\text { alterações em relação às } \\
\text { formas de trabalhar o } \\
\text { conhecimento } \\
\text { matemático com as } \\
\text { crianças. }\end{array}$ & $\begin{array}{l}\text { - Estudo das } \\
\text { características } \\
\text { predominantes da } \\
\text { infância. } \\
\text { - Começou a pensar a } \\
\text { Matemática voltada } \\
\text { para as crianças, } \\
\text { levando em conta } \\
\text { seus gostos, } \\
\text { interesses, } \\
\text { necessidades, } \\
\text { desenvolvimento } \\
\text { cognitivo, social e } \\
\text { afetivo. }\end{array}$ & $\begin{array}{l}\text { - Cita a disciplina de } \\
\text { Conteúdos, } \\
\text { Metodologia } \\
\text { Prática de Ensino de } \\
\text { Matemática. } \\
\text { - Considera que os } \\
\text { conteúdos } \\
\text { aprendidos a fizeram } \\
\text { pensar que seus } \\
\text { conhecimentos de } \\
\text { anteriores } \\
\text { Matemática eram } \\
\text { insuficientes para } \\
\text { que ela ensinasse } \\
\text { essa disciplina. } \\
\text { Afirma que ainda } \\
\text { possui dificuldades, } \\
\text { mas, se diz disposta a } \\
\text { estudar se for } \\
\text { exercer a docência. }\end{array}$ \\
\hline $\mathrm{S} 2$ & $\begin{array}{l}\text { - Cita Psicologia da } \\
\text { Educação, cursada no } \\
\text { 1ㅇ ano (fases de } \\
\text { aprendizagem); } \\
\text { - Afirma que o } \\
\text { professor de } \\
\text { Matemática deve } \\
\text { saber ensinar de } \\
\text { várias formas } \\
\text { diferentes. }\end{array}$ & $\begin{array}{l}\text { - Cita a disciplina } \\
\text { Didática. } \\
\text {-Acredita que hoje já } \\
\text { seria mais fácil ensinar os } \\
\text { conteúdos matemáticos } \\
\text { às crianças. }\end{array}$ & $\begin{array}{l}\text { - Cita a disciplina } \\
\text { Didática. } \\
\text { - Tal disciplina } \\
\text { contribuiu para que } \\
\text { ela se sentisse mais } \\
\text { segura em usar a } \\
\text { matemática na sala } \\
\text { de aula nos anos } \\
\text { iniciais. }\end{array}$ & $\begin{array}{l}\text { - Cita a disciplina } \\
\text { Conteúdos, } \\
\text { Metodologia } \\
\text { Prática de Ensino de } \\
\text { Matemática como } \\
\text { importante para que } \\
\text { ela perdesse o medo } \\
\text { da Matemática e } \\
\text { aprendesse formas } \\
\text { de ensinar esse } \\
\text { conhecimento. }\end{array}$ \\
\hline
\end{tabular}

Quadro 2: Síntese dos textos produzidos nos anos de 2007 a 2010. (Relação boa-RB e Relação regular - RR com a

Matemática)

Ao analisar os principais pontos levantados pelos sujeitos que apontavam no primeiro ano uma relação boa e regular com a Matemática (Quadro 2), percebemos que já no primeiro ano do curso citam a importância das disciplinas de Fundamentos (História da Educação, Filosofia da Educação e Psicologia da Educação). Nos textos completos eles citam que essas disciplinas auxiliam a ter uma visão mais ampla e crítica da Educação e apontam isso como importante para a Matemática. A partir do segundo ano e terceiro, após cursar Didática e Metodologias de disciplinas específicas levantam a importância de aspectos relacionados a metodologias de ensino. No quarto ano, destacam a disciplina específica voltada para Matemática e as contribuições são no sentido de refletir sobre novas formas de ver esse conhecimento e também sobre a forma de ensino, diferente do que vivenciaram. 


\begin{tabular}{|c|c|c|c|c|}
\hline & Textos 2007 & Textos 2008 & Textos 2009 & Textos 2010 \\
\hline RRU & $\begin{array}{l}\text { - Nos diferentes } \\
\text { textos estudados no } \\
\text { primeiro ano, a } \\
\text { Matemática aparece } \\
\text { quando tratam de } \\
\text { porcentagem nos } \\
\text { textos de Sociologia } \\
\text { da Educação e } \\
\text { Filosofia r da } \\
\text { Educação. }\end{array}$ & $\begin{array}{lr}\text { - Cita estudos } & \text { sobre } \\
\text { Paulo Freire, Educação } \\
\text { de Jovens e Adultos e seu } \\
\text { envolvimento em } & \text { grupos } \\
\text { de estudo } & \text { como } \\
\text { essenciais } & \text { para } \\
\text { compreender } & \text { a } \\
\text { importância de } & \text { se } \\
\text { aprender bem } & \text { o } \\
\text { conhecimento } & \\
\text { matemático para } & \text { poder } \\
\text { ensiná-lo. } & \end{array}$ & 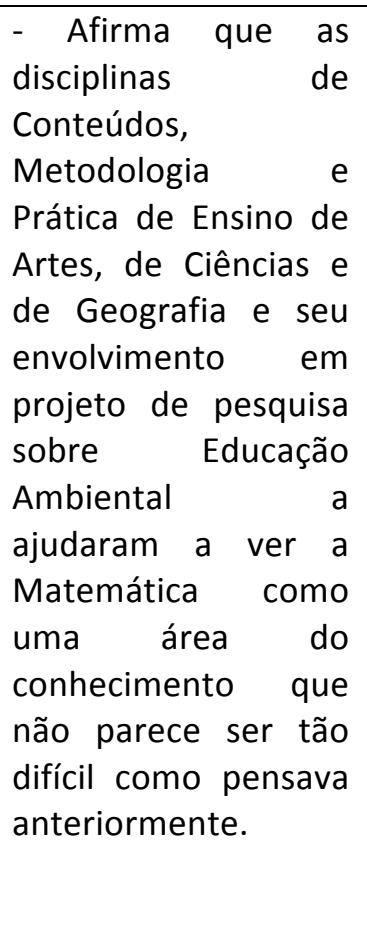 & $\begin{array}{l}\text { - Cita a disciplina } \\
\text { Conteúdos, } \\
\text { Metodologia } \\
\text { Prática de Ensino de } \\
\text { Matemática, cursada } \\
\text { no quarto ano. } \\
\text { - Os conhecimentos } \\
\text { aprendidos a fizeram } \\
\text { entender } \\
\text { importância da } \\
\text { Matemática a ser } \\
\text { ensinada aos alunos. } \\
\text { Relata que aprendeu } \\
\text { a fazer a conta da } \\
\text { divisão com dois } \\
\text { números na chave e } \\
\text { acredita que toda a } \\
\text { sua turma parece ter } \\
\text { melhorado a relação } \\
\text { com a Matemática. }\end{array}$ \\
\hline S4 & $\begin{array}{l}\text { - No 10 ano diz ter } \\
\text { aprendido a pensar } \\
\text { com as aulas de } \\
\text { Filosofia e de } \\
\text { Sociologia e acredita } \\
\text { que o mesmo } \\
\text { acontecerá até o fim } \\
\text { do curso, em relação } \\
\text { à Matemática. }\end{array}$ & $\begin{array}{l}\text { - Nos dois primeiros anos } \\
\text { foram reforçados alguns } \\
\text { fatores: ser simples, } \\
\text { atencioso, cuidadoso e a } \\
\text { importância de mostrar } \\
\text { ao aluno que você tem } \\
\text { compromisso frente a } \\
\text { sua sala. Diz que o que } \\
\text { pensa sobre a } \\
\text { Matemática ainda não } \\
\text { mudou. }\end{array}$ & $\begin{array}{l}\text { - Nos três primeiros } \\
\text { anos, tudo o que } \\
\text { aprendeu, afirma que } \\
\text { não interferiu na } \\
\text { forma como vê a } \\
\text { Matemática e seu } \\
\text { ensino. }\end{array}$ & $\begin{array}{l}\text { - Os conhecimentos } \\
\text { aprendidos no curso } \\
\text { de Pedagogia não } \\
\text { interferiram na } \\
\text { forma como ela vê a } \\
\text { Matemática } \\
\text { - Com a disciplina } \\
\text { Conteúdos, } \\
\text { Metodologia } \\
\text { Prática de Ensino de } \\
\text { Matemática } \\
\text { aprendeu a gostar } \\
\text { mais da Matemática, } \\
\text { ao menos dos } \\
\text { conteúdos dos anos } \\
\text { iniciais. }\end{array}$ \\
\hline
\end{tabular}

Quadro 3: Síntese dos textos produzidos nos anos de 2007 a 2010. (Relação ruim - RRU e Relação péssima - RP com

a Matemática)

De acordo com o Quadro 3, o sujeito que afirmava ter uma relação ruim com a Matemática no primeiro ano, no decorrer do curso, foi se envolvendo em grupos de estudos acadêmicos e isso interferiu na sua visão. Tal sujeito começou a perceber a importância de domínio de conceitos a serem ensinados tanto nas metodologias como em outros projetos do curso. No quarto ano, ao cursar a disciplina Conteúdos, Metodologia e Prática de Ensino de Matemática, demonstra satisfação em ter aprendido conceitos que não dominava e afirma que de forma geral notou uma mudança de olhar de todos os alunos do curso de Pedagogia da sua sala. 
Quanto ao sujeito que descrevia uma péssima relação com a Matemática no primeiro ano, ainda percebemos um certo receio em relação à Matemática. Nos três primeiros anos do curso, afirma que não mudou a forma de se relacionar com a Matemática e mesmo no último ano, apesar de afirmar que "aprendeu a gostar mais da Matemática", prossegue afirmando que os conhecimentos aprendidos no curso não mudaram a forma de se relacionar com essa área do conhecimento. É interessante observar que esse sujeito trabalhou numa escola como funcionário da secretaria durante todo o curso e não se envolveu em projetos de estudo na Universidade. Em seus relatos, há vários episódios traumáticos com relação a sua experiência em sala de aula em Matemática.

Em linhas gerais, os discursos dos sujeitos revelam alterações. Tais alterações indicam que eles terminam o curso mais próximos do conhecimento matemático, afirmam a necessidade de constante estudo sobre essa área e ao que parece há rupturas de crenças como aquelas que consideram ser a matemática inacessível. Entendemos que essas alterações estão relacionadas às diferentes disciplinas do curso, mas também à participação em projetos de iniciação científica, grupos de estudo, estágios nas escolas e às experiências vivenciadas como alunos da Educação Básica.

Constatamos que os sujeitos que ingressaram no curso vindos diretamente do Ensino Médio apresentam uma diferença em relação aos que já tinham experiência quanto ao exercício da docência. Temos sujeitos que ingressaram no curso sem qualquer experiência no campo profissional da Educação. Os saberes desses indivíduos estão relacionados a todo o processo que vivenciaram na Educação Básica como alunos. Ocorre que, com relação ao conhecimento matemático, as experiências que estes sujeitos descrevem, em geral, foram marcadas por conflitos, medos, angústias, baseadas em treinos e mecanizações e não auxiliaram de forma que ocorresse aprendizagem de conceitos matemáticos. As experiências descritas por esses sujeitos funcionam como filtro para a apropriação e (re)construção dos saberes desenvolvidos durante o curso por meio das diferentes disciplinas e/ou atividades extra curriculares. Consideramos fundamental que seja possível, no curso de Pedagogia, momentos de reflexão a partir das experiências desses jovens futuros professores.

Tardif (2010) e Serrazina (2003) confirmam a importância desse processo de reflexão sobre as experiências vividas para que sejam possíveis rupturas e ressignificações necessárias ao exercício da docência.

Percebemos um movimento na visão dos sujeitos em relação à natureza do conhecimento matemático no sentido de uma desmitificação desse conhecimento o que, de certo modo caracteriza uma maior aproximação desses futuros professores com a matemática, admitindo a possibilidade de uma relação dos alunos com essa disciplina distinta daquela que tiveram. Sujeitos que inicialmente afirmavam ter medo, que descreviam muitos conflitos vivenciados na educação básica no contato com a Matemática, e que se consideravam incapazes de aprender os conceitos matemáticos, no final do curso demonstram uma maior tranquilidade e chegam a afirmar que tal conhecimento pode ser tão difícil quanto os das outras áreas do conhecimento. Consideramos que há uma tendência para a compreensão do conhecimento matemático como construção humana que se aproxima da visão de Ernest (1991) quando este defende as posições falibilistas, as quais consideram a Matemática como produto de mudança social. O fato dos sujeitos afirmarem ao final 
do curso que apesar de dificuldades com alguns conceitos específicos, desenvolveram uma visão de maior proximidade em relação ao conhecimento matemático pode ter relações com o processo de reflexão sobre a natureza deste conhecimento durante o curso.

Para Charlot (2005) é importante considerarmos o processo de construção e reconstrução do saber. Cada sujeito organiza e categoriza seu mundo a partir das suas experiências e a partir delas pode se transformar. No presente estudo foi possível perceber as alterações dos diferentes sujeitos ao longo do curso em relação aos saberes sobre o conhecimento de matemática e seu ensino.

Os sujeitos da pesquisa demonstraram também a preocupação com os diferentes saberes que envolvem a docência apontados por Shulman (1986): conhecimento de conteúdo, conhecimento pedagógico geral, conhecimento de currículo, conhecimento pedagógico de conteúdo, conhecimento dos alunos, conhecimento de contextos educacionais e conhecimento de finalidades educacionais, propósitos e valores.

Consideramos que ao final do curso de Pedagogia, os sujeitos expressaram preocupações relacionadas:

- à articulação dos seus saberes da experiência aos saberes ensinados nas disciplinas do curso;

- aos saberes pedagógicos gerais relacionados à relação professor-aluno e suas implicações para o ensino de Matemática;

- aos saberes pedagógicos dos conteúdos matemáticos;

- à segurança ao se colocarem como aprendizes dos conceitos matemáticos através de um processo de desconstrução de formas equivocadas de trabalho com esses conceitos;

- à noção do quê e de como ensinar nos anos iniciais do Ensino Fundamental ainda que reconhecendo suas limitações quanto ao domínio dos conceitos matemáticos;

- ao conhecimento matemático como construção humana, diminuindo assim os preconceitos em relação a esse conhecimento;

- à importância que tem para os alunos o compromisso do professor em desejar fazer um bom trabalho na sala de aula;

- à preocupação com a relação professor-aluno como uma das condições favoráveis para se ensinar conceitos matemáticos.

\section{CONCLUSÃO}

Destacamos no presente trabalho a importância das características de um estudo longitudinal, na medida em que podemos visualizar as falas dos sujeitos no decorrer do tempo e perceber alterações, bem como, variações dessas alterações considerando o perfil de cada indivíduo investigado. De forma mais específica, como as relações com o conhecimento matemático dos alunos do curso de Pedagogia foram se modificando ao longo de quatro anos. Neste contexto, é importante salientar que as alterações percebidas nas falas dos sujeitos 
envolvidos na pesquisa são consequências não apenas dos saberes acadêmicos, presentes nas diferentes disciplinas desde o primeiro ano do curso, mas também das características individuais de cada sujeito, das experiências vividas como alunos da Educação Básica, das experiências como docente e da ausência de experiência como professor.

Durante o estudo, os sujeitos foram citando disciplinas que contribuíram para que eles pensassem de forma diferente em relação à Matemática e seu ensino, mesmo que estas disciplinas não mantivessem uma articulação direta com essa área do conhecimento. Citam as disciplinas de Fundamentos, todas as metodologias, Psicologia, Didática, Educação de Jovens e Adultos, Aprofundamento teórico em Paulo Freire. Também foram descrevendo experiências como alunos da Educação Básica quanto ao contato com a Matemática. Percebemos haver uma maior dificuldade em se aproximar do conhecimento matemático por parte daqueles sujeitos que tiveram uma quantidade maior e mais intensa de conflitos.

Uma característica consensual que apareceu no estudo foi a compreensão dos sujeitos de que o ensino de conceitos matemáticos não deve ser feito de forma mecânica, superficial e deve acontecer de forma que tenha sentido para os alunos. Desejam enquanto professores, proceder de forma diferente das experiências que tiveram como alunos da Educação Básica.

Ao que parece, o curso de Pedagogia foi lapidando os diferentes saberes dos sujeitos, ao mostrar, nas diferentes disciplinas e de forma mais específica na de conteúdos e metodologia de Matemática, a possibilidade de fazerem diferente do que vivenciaram.

Outra característica importante é a preocupação dos sujeitos com a relação professoraluno. Reiteradas vezes nesses quatro anos afirmaram que esse profissional não deve ser autoritário. Deve ouvir os alunos, respeitar suas dúvidas, conhecer os procedimentos que eles utilizam para resolver problemas e ter muita paciência.

Também surgiram preocupações relacionadas ao ensino de Matemática sob a forma de sugestões metodológicas, como por exemplo: utilização de atividades diversificadas, brincadeiras, jogos, necessidade de explicar os conceitos de diferentes formas, utilização de diferentes materiais didáticos, necessidade de mostrar aplicações dos conceitos matemáticos.

Os sujeitos, ao final do estudo afirmaram que ainda sentiam uma certa insegurança em relação ao domínio dos conceitos matemáticos a serem ensinados nos anos iniciais, entretanto, eles se mostravam dispostos a estudar, com um diferencial importante, sem medo, sem receio dessa área do conhecimento. Ao que nos parece, os sujeitos modificaram a relação com o conhecimento matemático, mas não houve tempo suficiente para uma transformação em relação a todos os conceitos.

Em nossa compreensão, a principal alteração em relação ao conhecimento matemático foi no sentido de aproximação dos sujeitos na medida em que afirmaram que se sentem mais seguros se forem exercer a docência nos anos iniciais do Ensino Fundamental, pois conseguiram desconstruir a ideia de que o conhecimento matemático é algo inacessível. Demonstraram nos textos analisados que tal conhecimento pode ser ensinado com significado. 


\section{REFERÊNCIAS}

Azcárate, P. (1999). El conocimiento profesional: naturraleza, fuentes, organización y desarrollo, 8. U.Lisboa: Quadrante.

Bonamino, A. M. C. de, \& Oliveira, L. H. G. (2013). Estudos longitudinais e pesquisa na educação básica, 19 (38), 33-50. Brasília: Linhas Críticas.

Charlot, B. (2005). Relação com o saber, formação de professores e globalização: questões para a educação hoje (p.159). Porto Alegre: Artmed.

Cooney, T. J., \& Wiegel, H. G. (2003). Examining the mathematics in Mathematics Teacher Education. In: A. J. Bishop, M. A. Clements, C. Keitel, J. Kilpatrick, F. K. S. Leung (Orgs.), Second International Handbook of Mathematics Education (pp. 795-828). Dordrecht, Boston e London: Kluwer Academic Publishers.

Curi, E. (2005). A matemática e os professores dos anos iniciais. São Paulo: Musa Editora.

Decreto Lei no 5.692/71. (1971). Lei de Diretrizes e Bases da Educação Nacional.

Decreto Lei no 9.394/96. (1996). Lei de Diretrizes e Bases da Educação Nacional.

Ernest, P. (2004). What is the Philosophy of Mathematics Education? Philosophy of Mathematics Education Journal. Recuperado de: www. People.exeter.ac.uk/PErnest/pome18/PhoM_\%20for_ICME_04.htm

The philosophy of mathematics education. (1991). London, New York e Philadelphia: The Falmer Press.

Gatti, B. A. (2010). Formação de professores no Brasil: características e problemas. Educação \& Sociedade, 31(113), 1355-1379. Recuperado de http://www.cedes.unicamp.br

Gatti, B. A., \& Nunes, M.M.R. (Coord.). (2008). Formação de professores para o Ensino Fundamental: Instituições formadoras e seus currículos (Relatório final: Pedagogia). Fundação Carlos Chagas, São Paulo, SP, Brasil. Recuperado de: http://revistaescola.abril.com.br/edicoes02116/aberto/bernardete1.pdf

Hitchcock, G., \& Hughes, D. (1995). Research and the Teacher: a qualitative introduction to schoolbased research. London and New York: Routledge.

Lüdke, M, \& André, M. E. D. A. (1986). Pesquisa em educação: abordagens qualitativas. São Paulo: EPU.

Nacarato, A., Mengali, B. L. da S., \& Passos, C. L. B. (2009). A matemática nos anos iniciais do ensino fundamental: tecendo fios do ensinar e do aprender (Tendências em Educação Matemática). Belo Horizonte: Autêntica Editora.

Ortega, E. M. V. (2011). A construção dos saberes dos estudantes de Pedagogia em relação à Matemática e seu ensino no decorrer da formação inicial. (Tese de doutorado). Faculdade de Educação da USP - FEUSP, São Paulo, SP, Brasil.

Poli, E. C. (2007). Estudo Longitudinal em Matemática: possibilidades e leitura de uma realidade do Ensino Fundamental. (Tese de doutorado). Universidade Estadual de Campinas - Unicamp, Campinas, SP, Brasil.

Resolução CNE/CP1/2006. (2006). Estabelece as diretrizes curriculares do curso de Pedagogia. Diário Oficial da União. Seção 1 (06-05-16). p.11. 
Santos, V. M. (2008). Percursos em Educação Matemática: ensino, aprendizagem e produção de conhecimento. (Tese Livre- Docência). Faculdade de Educação da USP - FEUSP, São Paulo, SP, Brasil.

Serrazina, L. (2003). A Formação para o ensino da Matemática: perspectivas futuras. In: Educação Matemática em Revista, 10(14).

Shulman, L. (1986). Those Who understand: Knowledge growth in teaching, 15(2), 4-14. Educational Researcher.

Stephens, M. (2003). Regulating the entry of teachers of mathematics into the profession: Challenges, new models, and glimpses into the future. In: In: A. J. Bishop, M. A. Clements, C. Keitel, J. Kilpatrick, F. K. S. Leung (Orgs.), Second International Handbook of Mathematics Education (pp. 767-793). London: Kluwer Academic Publishers.

Tardif, M. (2010). Saberes docentes e formação profissional. (10a ed). Petrópolis: Vozes. 